Preprints of the

Max Planck Institute for

Research on Collective Goods

Bonn 2010/03

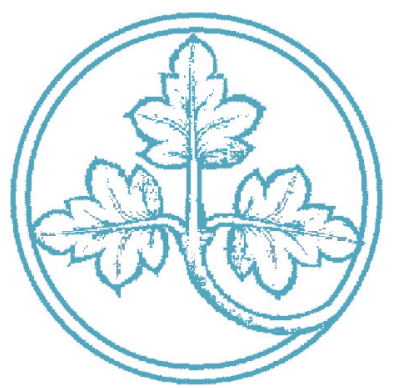

Switching Consumers

and Product Liability:

On the Optimality of

Incomplete Strict Liability

Florian Baumann

Tim Friehe

Kristoffel Grechenig

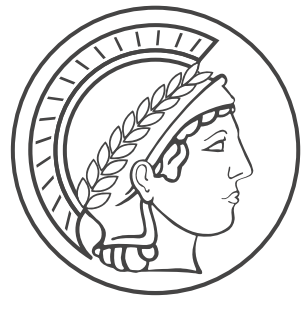




\section{Switching Consumers and Product Liability: On the Optimality of Incomplete Strict Liability}

Florian Baumann / Tim Friehe / Kristoffel Grechenig

December 2009 


\title{
Switching Consumers and Product Liability: On the Optimality of Incomplete Strict Liability
}

\author{
Florian Baumann* Tim Friehe ${ }^{\dagger} \quad$ Kristoffel Grechenig ${ }^{\ddagger}$
}

January 13, 2010

\begin{abstract}
This paper shows that it may be socially optimal to grant accident victims less than full compensation. In our framework, firms are liable under product liability but also invest in care to prevent consumers switching to competitors. Affecting the partition of consumers by means of care-taking is not desirable from a social standpoint. Consequently, it may be optimal to reduce liability below full compensation in order to adjust firms' care incentives.
\end{abstract}

Keywords: Tort law; product liability; care level; asymmetric information; switching JEL-Code: K 13

*Eberhard Karls University, Department of Economics, Melanchthonstr. 30 72074, Tübingen, Germany; florian.baumann@uni-tuebingen.de.

${ }^{\dagger}$ University of Konstanz, Department of Economics, Fach D136, 78457 Konstanz; tim.friehe@unikonstanz.de.

¥Max-Planck-Institute for Research on Collective Goods, Bonn, grechenig@coll.mpg.de, KurtSchumacher-Strasse 1053113 Bonn, Germany, (0049)22891416-51; grechenig@coll.mpg.de; University of St. Gallen, Department of Law. We would like to thank Anne van Aaken, Ulrich Berger, Christoph Engel, Sven Fischer, Benjamin Hilbig, Andreas Glöckner, Laszlo Goerke, Sebastian Kube, Albert Moik, Urs Schweizer, Emanuel Towfigh, Ansgar Wohlschlegel and the participants of the 4th French-German Talks in Law and Economics and of the MPI-Workshop in Bonn, October 2009 for discussion and comments. 


\section{Introduction}

Victims of product-related accidents are usually not fully compensated. This holds, for instance, because nonpecuniary losses are often not actionable (see, e.g., Endres and Lüdecke 1998; Posner 1998; Shavell 2004). In the standard framework of the economic analysis of tort law, less than full compensation will induce inefficient care choices if injurers are individuals, or if injurers are firms but victims are strangers (Shavell 2007). Given perfect information, less than full compensation does not cause inefficiencies if injurers are firms and victims are consumers. This holds because consumers consider their total costs entailing both the price paid to the firm and the expected harm borne by the consumer. Under perfect information, whether expected liability is allocated more towards the firm or the consumer is therefore without consequence for the efficiency of the outcome. In contrast, the literature on product liability finds that if consumers are imperfectly informed, imposing full liability on the firm is justified for efficiency reasons in most circumstances (Geistfeld 2009). From that perspective, the practice of not fully compensating accident victims may be seen as inefficient.

We show that it may be efficiency-enhancing to grant accident victims less than full compensation. In our product-liability setting, firms may invest excessively in care in order to attract customers. This makes it socially optimal to reduce firm liability below the level of full victim compensation in order to adjust care incentives.

Our result is derived within the following framework. Two heterogenous firms compete via prices and precaution in two periods, in which consumers do not observe care invested by the firm before the purchase of the good, but form rational expectations regarding the level of precaution. We consider the product to be an experience good, i.e. consumers become informed about the level of precaution after the purchase, which often holds true in reality (Polinsky and Shavell, forthcoming). More precisely, consumers get informed about the probability of product-related accidents for each firm. This information may be provided by, e.g., consumer safety groups and allows for an assessment of care taken by firms. Given first-period care choices by both firms, in the second period consumers are attracted to the firm with relatively high care, i.e. consumers punish firms whose products were characterized by a relatively higher accident probability. Firms anticipate this switching of consumers due to a comparison of first-period precaution levels and exert excessive precaution if victim compensation is full. 
In our set-up, consumer choice of one of the two firms in the second period depends on firms' first-period care choices. In making this assumption, we incorporate the fact that consumers may perceive a firm supplying a good in period 1 with a relatively low care level as unfair. Empirical evidence from studies investigating reciprocal behavior shows that the perception of being treated unfairly provokes retaliatory action (see, e.g. Fehr, Kirchsteiger and Riedl 1993; Fehr, Gächter and Kirchsteiger 1997; Bewley 1999; Fehr and Gächter 2000; Hannan, Kagel and Moser 2002; Kube, Maréchal and Puppe 2007). There are theoretical papers which explicitly draw on these findings (see, e.g., Rabin 1993; Falk and Fischbacher 2006). Our framework is conceptually very close to the study by Huck and Tyran (2007), which analyzes reciprocal consumers who punish firms for providing low quality by terminating the relation to the supplier. ${ }^{1}$ In an experimental setting, Renner and Tyran (2004) show that this kind of reciprocity increases average product quality, a finding consistent with our argument. As an empirical case in point for our setting, the accounting company KPMG Germany suffered an unusual loss of clients subsequent to a well-publicized auditing failure in 2002 (Weber et al. 2008). In our case, retaliatory action by consumers also takes the form of switching the supplier, possibly even if other characteristics of the goods are equal. As a consequence, firms would exert precaution even if product liability were absent. This argument is also forcefully made in Polinsky and Shavell (forthcoming). We argue, therefore, that it may be efficiency-enhancing not to compensate accident victims to the full extent. The combined force of the threat of consumer switching and full liability would otherwise provoke excessive precaution.

In the literature on the economic analysis of tort law, the level of compensation and deviations from awarded damages to the level of harm have often been subject to scrutiny (Visscher 2009). Cooter and Porat (2001) present an initial analysis of the consequences of nonlegal sanctions on the optimal level of compensation, also relating to reputational concerns. In addition, four areas are of particular importance. First, usually not all cases are filed. This calls for compensation in excess of the harm suffered in accordance with the punitive damages multiplier (Shavell 2007). Second, it may be that injurers are incapable of compensating victims in some cases, i.e. that injurers are judgment proof. It has been shown

\footnotetext{
${ }^{1}$ More generally, our model contributes to the literature that models consumers as partly irrational (see, e.g, DellaVigna and Malmendier 2004; Köszegi 2005; Eliaz and Spiegler 2006; Heidhues and Köszegi 2008; Heidhues and Köszegi 2009).
} 
for the case in which the magnitude of harm is uncertain that, from a policy perspective, it may be optimal for care incentives to lower (increase) compensation below (above) the level of harm for some realizations of the random harm variable (see, e.g., Lewis and Sappington 1999). Third, victims are often heterogeneous with respect to the level of harm suffered in the event of an accident. This brings the accuracy of damages and the value of accurate damages into focus (Kaplow and Shavell 1996). Finally, if parties to the accident are risk averse and strict liability applies, it is optimal to compensate less than the level of harm as a consequence of accounting for risk-bearing costs in social costs, and induce risk-sharing (Shavell 2007). All of these additional aspects have no direct bearing on our pursuit.

There is a vast literature on the economics of product liability (see Geistfeld 2009 for a recent survey). For instance, Daughety and Reinganum (2008) consider voluntary disclosure of risk-related information via price signaling or costly disclosure, two aspects from which we abstract. We also do not consider the possibility of contractually specified liability or warranties. In this realm, Wickelgren (2006) argues that consumers will waive liability in order to obtain a lower price because the precautionary decision by the firm is already made at that point in time. Consequently, mandatory product liability, which we consider, is a way to commit to not waiving liability. Product liability affects firm decision-making in several ways. For instance, it has been established that product liability may also impact on product differentiation (Endres and Lüdecke 1998). Despite this wide array of analyses in the field of product liability, the topic we wish to analyze has not yet been the subject of scrutiny.

The structure of this paper is as follows. Section 2 describes the model. Section 3.1 presents the analysis, where firms determine price and care levels for a given level of firm liability. Section 3.2 presents decision-making by the social planner. The social planner decides on the level of firm liability, taking in account the way in which firms respond to a given level of firm liability. Section 4 concludes the study.

\section{The Model}

We keep the model simple in order to focus on the firms' incentives for overinvestment in care and the appropriate response on the part of the social planner. The model comprises two periods, $t=1,2$. We consider two firms and a mass of consumers equal to two. The latter are 
evenly distributed on the interval [0,2], analogous to Hotelling (1929). The firms' locations on the interval are given by 0 and 2 , respectively, where the distance of consumers to firms indicates the costs incurred by consumers resulting from the misfit between consumers' most favored variety of the product, on the one hand, and the features of the product actually produced by a firm, on the other. Consumers buy one unit of the product in each period from either of the two firms. Consuming the product might entail harm for the consumer, which may vary for each incident. Expected harm is equal to $h=1$. The probability of harm actually occurring is given by $\left(1-x_{i t}\right)$ per unit of the product, where $x_{i t}, 0 \leq x_{i t} \leq 1$, measures care taken by firm $i, i=1,2$ in period $t$. The choice between firms is guided, first, by prices charged by the competing firms; second, by expectations about expected harm borne by the consumer; and third, by the distances to firms, given a consumer's position on the interval. Furthermore, we assume that in the second period, consumers may also be guided by reported accident history of firms in period 1 . To reflect this in the simplest way possible, we assume consumers' preferences are shifted in favor of the firm with relatively few accidents in the first period. The extent of the shift of the interval is given by the difference in accident probabilities in the first period, $\left(1-x_{i 1}\right)-\left(1-x_{j 1}\right)$, $i, j=1,2, j \neq i$, weighted by the parameter $\alpha \geq 0$. The parameter $\alpha$ represents the force of the reciprocity considerations discussed in the introduction. Assuming, without loss of generality, $x_{11} \geq x_{21}$, the new boundaries of the interval in which consumers are located are given by $\left[-\alpha\left(x_{11}-x_{21}\right),\left(2-\alpha\left(x_{11}-x_{21}\right)\right)\right]$ in the second period.

Besides competing in care, the level of which determines the probability of an accident, firms compete in setting prices. With respect to care, firm $i$ bears care costs per unit produced of $C\left(x_{i t}\right)=x_{i t}^{2}$, which are increasing and strictly convex in care. Strict liability applies according to modern Western legal regimes on product liability (Zweigert and Kötz 1998; Shavell 2004). The share of harm borne by the firm in the case of an accident is denoted by $\gamma$ and may be less than one, $\gamma \leq 1$. We assume that if harm varies, the precise level of harm cannot be observed by courts, which therefore take recourse to expected harm when determining the level of damages. ${ }^{2}$ We abstract from production costs, so that firm $i$ bears $x_{i t}^{2}+\gamma\left(1-x_{i t}\right)$ as expected costs per unit of output. Consumers know that firms bear

\footnotetext{
${ }^{2}$ This assumption implies that even for $\gamma=1$, some consumers who experienced an accident are not made whole and therefore might seek retaliatory action in the second period. However, the analysis and our results are unaffected if we assume that the level of harm is always equal to $h=1$.
} 
a share $\gamma$ of expected harm but cannot observe care actually taken by the firm. Consumer demand for firm $i$ is therefore dependent on expected care $E\left(x_{i t}\right)$ and $E\left(x_{j t}\right)$ as well as prices charged, $p_{i t}$ and $p_{j t}, i, j=1,2, i \neq j$. We assume that consumers will form correct expectations about actual care-taking.

To derive the demand function for each firm, we analyze the decision made by consumers regarding where to buy the product. In both periods, a consumer located at point $z$ will buy the product from firm 1, located at zero, if costs incurred are lower than buying the product from firm 2. This comparison of costs includes the distance costs $z$, respectively $2-z$, the prices charged by firms and expected harm born by the consumer for $\gamma<1$. Accordingly, the consumer chooses the product of firm 1 if

$$
z+p_{1 t}+(1-\gamma)\left(1-E\left(x_{1 t}\right)\right)<(2-z)+p_{2 t}+(1-\gamma)\left(1-E\left(x_{2 t}\right)\right)
$$

so that the critical consumer who is simply indifferent with regard to buying the product from firm 1 or 2 is located at

$$
z_{t}^{*}=1+\frac{p_{2 t}-p_{1 t}+(1-\gamma)\left[\left(1-E\left(x_{2 t}\right)\right)-\left(1-E\left(x_{1 t}\right)\right)\right]}{2}
$$

Therefore, given the symmetry of the model, the demand for firm $i$ in period $1, D_{i 1}$, is given by

$$
D_{i 1}=D_{i 1}\left(p_{i 1}, p_{j 1}\right)=1+\frac{\left.\left.p_{j 1}-p_{i 1}+(1-\gamma)\left[E\left(x_{i 1}\right)\right)-E\left(x_{j 1}\right)\right)\right]}{2}
$$

This formula clearly shows that firm $i$ may gain consumers from firm $j$ if its product is more attractive for the consumer due to a lower price or higher expected care-taking by firm $i$. The latter is important for the consumer because he/she bears the fraction $(1-\gamma)$ of the expected harm which occurs with probability $\left(1-x_{i 1}\right)$. Note, that expected care is not directly determined by firms. Instead prices charged by firms have a direct impact on demand. Profits of firm $i$ in period 1 follow as

$$
\pi_{i 1}=\left(p_{i 1}-x_{i 1}^{2}-\gamma\left(1-x_{i 1}\right)\right) D_{i 1}
$$

In the second period, consumers have observed firms' first-period care choices. The preference interval shifts according to the parameter $\alpha$ and the number of accidents actually occurring with the firms' products respectively. This changes firm-specific demand when compared to demand in period 1. Allowing for this behavior, demand in period 2 for firm $i$ 
can be stated as

$$
D_{i 2}=D_{i 2}\left(p_{i 2}, p_{j 2}, x_{i 1}, x_{j 1}\right)=1+\alpha\left(x_{i 1}-x_{j 1}\right)+\frac{p_{j 2}-p_{i 2}+(1-\gamma)\left[E\left(x_{i 2}\right)-E\left(x_{j 2}\right)\right]}{2}
$$

directly depending on firms' choice of care in period 1 . The profits of firm $i$ in period 2 are given by

$$
\pi_{i 2}=\left(p_{i 2}-x_{i 2}^{2}-\gamma\left(1-x_{i 2}\right)\right) D_{i 2}
$$

\section{The Analysis}

In the following analysis, we will first focus on firm behavior, given a certain level of firm liability $\gamma$. Later on, we will consider the possibility that the planner decides on the level of firm liability $\gamma$ in order to attain the minimum level of social costs.

\subsection{Decentralized Outcome}

We first analyze decision-making in period 2. Firm $i$ maximizes profits (4) with respect to price and precaution. The set of first-order conditions that simultaneously determine the equilibrium outcome is given by

$$
\begin{aligned}
& \frac{\partial \pi_{i 2}}{\partial p_{i 2}}=D_{i 2}-\frac{1}{2}\left(p_{i 2}-x_{i 2}^{2}-\gamma\left(1-x_{i 2}\right)\right)=0 \\
& \frac{\partial \pi_{i 2}}{\partial x_{i 2}}=\left(-2 x_{i 2}+\gamma\right) D_{i 2}=0
\end{aligned}
$$

$i=1,2$, which are solved by

$$
\begin{aligned}
& p_{i 2}^{*}=2+\frac{8 \alpha\left(x_{i 1}-x_{j 1}\right)+4(1-\gamma)\left(E\left(x_{i 2}\right)-E\left(x_{j 2}\right)\right)+\gamma 3(4-\gamma)}{12} \\
& x_{i 2}^{*}=\frac{\gamma}{2}
\end{aligned}
$$

$i, j=1,2, i \neq j$.

There is no strategic interdependence between firm 1 and firm 2 regarding the level of care in period 2. Therefore, firms minimize the sum of care costs and damages per unit produced. This behavior will be understood by consumers, i.e., in equilibrium, $E\left(x_{i 2}\right)=\gamma / 2$ applies. We therefore obtain

$$
p_{i 2}^{*}=2+\frac{8 \alpha\left(x_{i 1}-x_{j 1}\right)+3 \gamma(4-\gamma)}{12}
$$


The price of firm $i$ is higher where the difference between care levels in period 1 is greater, because demand is shifted to a larger extent towards the firm with relatively high care. Furthermore, equilibrium prices increase with $\gamma$ because higher compensation requirements for firms result in higher marginal costs for the firm, as can be derived from applying the envelope theorem. Using the equilibrium outcomes, we calculate profits in period 2 as

$$
\pi_{i 2}=\frac{2}{9}\left(3+\alpha\left(x_{i 1}-x_{j 1}\right)\right)^{2}
$$

Equilibrium profits in period 2 depend on the difference in first-period care but are not affected by the level of damages $\gamma$. Given rational expectations, this results because any change in compensation requirements is completely offset by a corresponding change in the consumers' willingness to pay.

Next, we turn to decision-making in period 1. At this stage, firms anticipate that firstperiod care-taking affects profits in the second period. Consequently, the objective function to maximize in period 1 is the sum of first-period and second-period profits, where secondperiod profits are stated using equilibrium levels.

$$
\begin{aligned}
\Pi_{i} & =\pi_{i 1}+\pi_{i 2} \\
& =\left(p_{i 1}-x_{i 1}^{2}-\gamma\left(1-x_{i 1}\right)\right) D_{i 1}+\frac{2}{9}\left(3+\alpha\left(x_{i 1}-x_{j 1}\right)\right)^{2}
\end{aligned}
$$

The set of first-order conditions, which simultaneously determine the equilibrium outcome, is given by

$$
\begin{aligned}
\frac{\partial \prod_{i}}{\partial p_{i 1}} & =D_{i 1}-\frac{1}{2}\left(p_{i 1}-x_{i 1}^{2}-\gamma\left(1-x_{i 1}\right)\right) \\
& =1-p_{i 1}+\frac{p_{j 1}+(1-\gamma)\left[E\left(x_{i 1}\right)-E\left(x_{j 1}\right)\right]+x_{i 1}^{2}+\gamma\left(1-x_{i 1}\right)}{2}=0 \\
\frac{\partial \prod_{i}}{\partial x_{i 1}} & =\left(-2 x_{i 1}+\gamma\right) D_{i 1}+\frac{4 \alpha}{9}\left(3+\alpha\left(x_{i 1}-x_{j 1}\right)\right) \\
& =\left(-2 x_{i 1}+\gamma\right)\left(1+\frac{p_{j 1}-p_{i 1}+(1-\gamma)\left(E\left(x_{i 1}\right)-E\left(x_{j 1}\right)\right)}{2}\right) \\
& +\frac{4 \alpha}{9}\left(3+\alpha\left(x_{i 1}-x_{j i}\right)\right)=0
\end{aligned}
$$

$i, j=1,2, i \neq j$.

In our setting, first-period pricing does not affect profits in the second period. This is the reason why (12) equals the reaction function in standard duopolistic price competition. In contrast, first-period care has a direct effect on profits in period 2, in addition to its effect 
on profits in period 1. As indicated by (13), the additional benefits from first-period care regarding profits in period 2 induce the firm to choose a higher care level, $x_{i 1}^{*}>\gamma / 2=x_{i 2}^{*}$. Indeed, acknowledging correct expectations by consumers, i.e. $E\left(x_{i 1}\right)=x_{i 1}$, we find firstperiod equilibrium care, price levels and profits respectively to be

$$
\begin{aligned}
& p_{i 1}^{*}=2+\frac{\gamma(4-\gamma)}{4}+\frac{4 \alpha^{2}}{9} \\
& x_{i 1}^{*}=\frac{\gamma}{2}+\frac{2 \alpha}{3} \\
& \pi_{i 1}^{*}=2
\end{aligned}
$$

The care level in the first period is higher than the level of care a myopic firm would choose, which is $x_{i 1}=\gamma / 2$, whenever $\alpha>0$. This reflects the effect of first-period care on demand in period 2. Prices in the first period reflect that higher costs of care are shifted forward to consumers. Care increases in $\alpha$, so that an increase in $\alpha$ translates into an increase in prices.

Given (14) and (15), we are now able to state second-period equilibrium care and price levels as well as profits as functions of exogenous variables. We obtain

$$
\begin{aligned}
p_{i 2}^{*} & =2+\frac{\gamma(4-\gamma)}{4} \\
x_{i 2}^{*} & =\frac{\gamma}{2} \\
\pi_{i 2}^{*} & =2
\end{aligned}
$$

The above statement of the equilibrium price in period 2 allows for a quick comparison with the price chosen in period 1. The first-period price is higher than the second period price if $\alpha>0$. The potential switching of consumers induces firms to take higher care in period 1, which translates into higher first-period prices.

\subsection{Planner Intervention}

The model is kept simple by assuming that consumers purchase the good in both periods. This implies that care-taking and pricing decisions do not affect the volume of trade. Furthermore, a variation in the price level only implies a different distribution of rents between firms and consumers. We also find that profits are unaffected by the choice of the compensation requirement of firms $\gamma$ because $\pi_{i 1}^{*}=\pi_{i 2}^{*}=2$. Consequently, only consumer welfare will be affected by the choice of $\gamma$. Taken together, the efficiency-minded planner is concerned 
with the level of care taken and costs resulting from the distance between consumers and the location of firms. The objective function of the social planner can be stated as

$$
\begin{aligned}
\min S C= & \int_{0}^{z_{1}^{*}} z d z+\int_{z_{1}^{*}}^{2}(2-z) d z \\
& +z_{1}^{*}\left(x_{11}^{2}+\left(1-x_{11}\right)\right)+\left(2-z_{1}^{*}\right)\left(x_{21}^{2}+\left(1-x_{21}\right)\right) \\
& +\int_{-\alpha\left(x_{11}-x_{21}\right)}^{z_{2}^{*}} z d z+\int_{z_{2}^{*}}^{2-\alpha\left(x_{11}-x_{21}\right)}(2-z) d z \\
& +\left[z_{2}^{*}+\alpha\left(x_{11}-x_{21}\right)\right]\left(x_{12}^{2}+\left(1-x_{12}\right)\right)+\left[2-z_{2}^{*}-\alpha\left(x_{11}-x_{21}\right)\right]\left(x_{22}^{2}+\left(1-x_{22}\right)\right)
\end{aligned}
$$

where $z_{t}^{*}$ is the position of the indifferent consumer in period $t$. All consumers with $z \leq z_{t}^{*}$ will buy the product from firm 1 in period $t$. The first two (last two) lines in (20) state expected social costs in period 1 (2). These comprise costs due to the misfit of the product, i.e. the deviation of consumers' locations from firms, care costs and expected harm. As a first observation, care costs in period 2 only affect expected costs per unit of output produced. We can therefore conclude that first-best care is given by $x_{12}^{F B}=x_{22}^{F B}=1 / 2$, according to cost minimization in period 2. The first-order condition for $z_{2}^{*}$ then implies

$$
\frac{\partial S C}{\partial z_{2}^{*}}=2 z_{2}^{*}-2=0
$$

This allows us to deduce that the optimal level of $z_{2}^{*}$ is $z_{2}^{F B}=1$. Using these findings, the remaining first-order conditions are given by

$$
\begin{aligned}
& \frac{\partial S C}{\partial z_{1}^{*}}=2 z_{1}^{*}-2+\left(x_{11}^{2}+\left(1-x_{11}\right)\right)-\left(x_{21}^{2}+\left(1-x_{21}\right)\right)=0 \\
& \frac{\partial S C}{\partial x_{11}}=z_{1}^{*}\left(2 x_{11}-1\right)-2 \alpha^{2}\left(x_{11}-x_{21}\right)=0 \\
& \frac{\partial S C}{\partial x_{21}}=\left(2-z_{1}^{*}\right)\left(2 x_{21}-1\right)+2 \alpha^{2}\left(x_{11}-x_{21}\right)=0
\end{aligned}
$$

which are solved by $z_{1}^{F B}=1, x_{11}^{F B}=x_{21}^{F B}=1 / 2$. Again, the first-best level of care minimizes the expected social costs, i.e., the sum of precaution costs and expected harm per unit, whereas $z_{1}^{F B}$ minimizes distances between locations of consumers and firms.

The above describes the first-best allocation of consumers to firms and levels of precaution. The power of the regulator is not usually all-encompassing enough to simply impose this first-best outcome. As a consequence, we assume henceforth that the sole instrument of the planner is the share of expected harm which is borne by the firm, i.e., $\gamma$. In other terms, 
the planner accepts the way in which price and care levels are chosen by firms but tries to reach a second-best level of social costs by the use of the optimal $\gamma \cdot{ }^{3}$ This setting implies that the planner takes

$$
\begin{aligned}
x_{i 1}^{*} & =\frac{\gamma}{2}+\frac{2 \alpha}{3} \\
x_{i 2}^{*} & =\frac{\gamma}{2}
\end{aligned}
$$

and equilibrium prices as given. Given the symmetric outcome, the critical consumer is indeed located at $z_{t}^{F B}=1$ in both periods. With respect to care, note that first-period care is excessive relative to first-best care if the effect of switching consumers is sufficiently pronounced, i.e., $x_{i 1}^{*}>x_{i 1}^{F B}$ whenever $\alpha>\frac{3}{4}(1-\gamma)$. If the planner were to choose $\gamma=1$, first-period care is always excessive for $\alpha$ different from zero. In contrast, second-period care falls short of first-best care as soon as $\gamma<1$. The planner will trade-off these aspects when choosing $\gamma$ for a given $\alpha$ in the pursuit of minimizing total social costs.

Given $z_{t}=1$ in both periods, the planner minimizes total social costs of care and expected harm

$$
T S C=\sum_{i=1}^{2} \sum_{t=1}^{2}\left(x_{i t}^{* 2}+\left(1-x_{i t}^{*}\right)\right)
$$

with respect to $\gamma$. This results in the second-best solution

$$
\gamma^{S B}=1-\frac{2 \alpha}{3}
$$

We find that it is optimal to fully compensate accident victims only if there is no effect due to switching consumers, i.e., if $\alpha=0$. That is, if consumers react to the number of accidents observed in the first period by shifting demand in period 2, care incentives will be excessive if the full burden of expected harm were imposed on the firms.

Proposition 1 It is second best with respect to the minimization of social costs that the firm bears less than full expected harm whenever $\alpha>0$.

Proof. This proposition uses the argument leading to (26).

We have assumed that the planner is not in the position to choose firm liability contingent on the period. However, it is clear from our argumentation that if the planner can decide on liability contingent on the period, $\gamma_{t}, t=1,2$, the optimal combination of levels of

\footnotetext{
${ }^{3}$ Daughety and Reinganum (2006) consider a planner who is similarly restricted in his/her means.
} 
compensation requirement would be $\left(\gamma_{1}, \gamma_{2}\right)=\left(1-\frac{4 \alpha}{3}, 1\right)$. In other terms, the planner would impose full liability in the second period and impose less than full liability in the first period, if $\alpha>0$, to lessen the combined impact of liability and reputation. In this way, policymakers optimally manage the incentives from market forces and product liability. Moreover, the results imply that liability should be different for firms that sell "once in a lifetime" goods versus firms that sell products which are purchased on a more regular basis. The point is that less than full compensation is socially optimal in the presence of strong market forces due to repeated purchases.

\section{Conclusion}

It is an empirical regularity that compensation of accident victims is incomplete. Usually there are components of a victim's costs such as pain and suffering or time spent filing the claim which are not fully compensated by the injurer. This practice is in contrast to recommendations in the literature, arguing that consumers having imperfect information should lead to full liability of firms. This paper starts with imperfectly informed consumers and additionally incorporates behavioral findings suggesting potentially retaliatory consumer actions. Consumers may punish firms whose performance is dwarfed by that of competitors by switching the supplier. Firms care about upholding customer relationships and, given full liability, may thus be motivated to take precaution in excess of the level that minimizes social costs. An adequate policy response is to reduce the level of compensation below the level of harm. If regulators have sufficient information, such reductions in the level of compensation should depend on the specifics of the case, while they are advisable across the board otherwise. Consequently, this paper provides an explanation for the observed practice by taking into account the effects of market forces.

\section{References}

Bewley, T.F. (1999). Why Wages Don't Fall During a Recession. Cambridge, MA: Harvard University Press.

Cooter, R., and A. Porat (2001). Should Courts Deduct Nonlegal Sanctions from Damages? Journal of Legal Studies 30: 401-22.

DellaVigna, S., and Malmendier, U. (2004). Contract Design and Self-Control: Theory and 
Evidence. Quarterly Journal of Economics 119: 353-402.

Daughety, A., and J. Reinganum (2006). Markets, Torts and Social Inefficiency. The Rand Journal of Economics 37: 300-23.

Daughety, A., and J. Reinganum (2008). Products Liability, Signaling and Disclosure. Journal of Institutional and Theoretical Economics 164: 106-26.

Eliaz, K., and Spiegler, R. (2006). Contracting with Diversely Naive Agents. Review of Economic Studies 73: 689-714.

Endres, A., and A. Lüdecke (1998). Incomplete Strict Liability: Effects on Product Differentiation and Information Provision. International Review of Law and Economics 18: 511-28. Falk, A. and U. Fischbacher (2006). A Theory of Reciprocity. Games and Economic Behavior 54: 293-315.

Fehr, E., Kirchsteiger, G., and A. Riedl (1993). Does Fairness Prevent Market Clearing? An Experimental Investigation. Quarterly Journal of Economics 108: 437-460.

Fehr, E., Gächter, S., and G. Kirchsteiger (1997). Reciprocity as a Contract Enforcement Device. Econometrica 65: 833-860.

Fehr, E., and S. Gächter (2000). Fairness and Retaliation: The Economics of Reciprocity. Journal of Economic Perspectives 14: 159-81.

Geistfeld, M.A. (2009). Products Liability. In: Faure, M. (Ed.). The Encyclopedia of Law and Economics. 2nd edition. Edward Elgar.

Hannan, R., Kagel, J., and D. Moser (2002). Partial Gift Exchange in an Experimental Labor Market: Impact of Subject Population Differences, Productivity Differences and Effort Requests on Behavior. Journal of Labor Economics 20: 923-951.

Heidhues, P. and Köszegi, B. (2008). Exploiting Naivete about Self-Control in the Credit Market. Working Paper. University of California, Berkeley.

Heidhues, P. and Köszegi, B. (2009). Futile Attempt at Self-Control. Journal of the European Economic Association 7: 423-434.

Hotelling, H. (1929). Stability in Competition. Economic Journal 39: 41-57.

Huck, S., and J.R. Tyran (2007). Reciprocity, Social Ties, and Competition in Markets for Experience Goods. Journal of Socio-Economics 36: 191-203.

Kaplow, L., and S. Shavell (1996). Accuracy in the Assessment of Damages. Journal of Law and Economics 39: 191-210.

Köszegi, B. (2005). On the Feasibility of Market Solutions to Self-Control Problems. Swedish 
Economic Policy Review 12: 71-94.

Kube, S., Marechal, M., and C. Puppe (2007). Do Wage Cuts Damage Work Morale? Evidence from a Natural Field Experiment. Unpublished.

Lewis, T.R., and D.E.M. Sappington (1999). Using Decoupling and Deep Pockets to Mitigate Judgment-proof Problems. International Review of Law and Economics 19: 275-93.

Polinsky, A.M., and S. Shavell (forthcoming). The Uneasy Case for Product Liability. Harward Law Review.

Posner, R. (1998). Economic Analysis of Law. Aspen Publishers.

Rabin, M. (1993). Incorporating Fairness into Game Theory and Economics. American Economic Review 83: 1281-1302.

Renner, E., and J.R. Tyran (2004). Price Rigidity in Consumer Markets. Journal of Economic Behavior and Organization 55: 575-93.

Shavell, S. (2004). Foundations of Economic Analysis of Law. Cambridge, MA: Harvard University Press.

Shavell, S. (2007). Liability for Accidents. In: Polinsky, A.M., and S. Shavell (Eds.). Handbook of Law and Economics 1. Amsterdam: Elsevier, 139-82.

Visscher, L. (2009). Tort Damages. In: Faure, M. (Ed.). The Encyclopedia of Law and Economics. 2nd edition. Edward Elgar.

Weber, J., M. Willenborg, and J. Zhang (2008). Does Auditor Reputation Matter? The Case of KPMG Germany and ComROAD AG. Journal of Accounting Research 46: 941-72. Wickelgren, A. (2006). The Inefficiency of Contractually-Based Liability with Rational Consumers. Journal of Law, Economics, and Organization 22: 168-83.

Zweigert, K., and H. Kötz (1998). An Introduction to Comparative Law. Oxford: Oxford University Press.

\section{Authors}

Florian Baumann

Eberhard Karls University, Department of Economics

Melanchthonstr. 30

72074 Tübingen, Germany

florian.baumann@uni-tuebingen.de 
Tim Friehe

University of Konstanz, Department of Economics

Fach D136, 78457 Konstanz

tim.friehe@uni-konstanz.de

Kristoffel Grechenig

Max-Planck-Institute for Research on Collective Goods

Kurt-Schumacher-Strasse 10

53113 Bonn, Germany

grechenig@coll.mpg.de, (0049)22891416-51

University of St. Gallen, Department of Law

Bodanstr. 4

9000 St. Gallen, Switzerland 